RESENHA

\title{
Resenha da obra Didática no cárcere II: entender a natureza para entender o ser humano e o seu mundo
}

\author{
Carolina Bessa Ferreira de Oliveira
}

SILVA, R. (org.). Didática no cárcere II: entender a natureza para entender o ser humano e o seu mundo. São Paulo: Giostri, 2018.

A obra Didática no cárcere II: entender a natureza para entender o ser bumano e o seu mundo foi organizada por Roberto da Silva e publicada, em 2018, pela Editora Giostri. Resulta de um processo coletivo de produção de conhecimento, que se iniciou com uma versão experimental de 2017, com tiragem limitada aos profissionais envolvidos - cujo contexto se relaciona a processo formativo desencadeado pela Faculdade de Educação da Universidade de São Paulo (FE-USP) em parceria com a Diretoria Regional de Ensino Centro-Oeste da Secretaria da Educação do Estado de São Paulo.

A obra pauta-se no desafio de elaborar uma proposta metodológica destinada à educação nos espaços de privação de liberdade. E publicada após experimentação em salas de aula de unidades prisionais e de centros de internação de adolescentes em medida socioeducativa, resultando de uma experiência que envolveu cerca de cem profissionais da educação em doze meses de trabalho.

Esse processo iniciou-se no âmbito de um curso de aperfeiçoamento voltado a professores da rede estadual que atuavam em unidades do entorno do Campus Butantã, na capital paulista, onde se situa a FE-USP ${ }^{1}$. Destinou-se a oferecer conteúdos atualizados, bem como promover trocas de experiências e atividades em grupo voltadas à autoria coletiva, que refletissem cada componente teórico e suas didáticas, desdobrando-se em matrizes de aprendizagem.

O autor organizador da obra, cuja trajetória pessoal e profissional é diretamente relacionada à privação de liberdade, com vasta experiência, é doutor em Educação e lidera o Grupo de Estudos e Pesquisas sobre Educação em Regimes

1 Trata-se do curso Docência em Regimes de Privação de Liberdade, ofertado em 2017. Disponível em: https://uspdigital.usp.br/apolo/apoObterCurso?cod_curso=480200003\&cod_ edicao=16001\&numseqofeedi=1. Acesso em: 15 mar. 2020.

Universidade Federal do Sul da Bahia, Porto Seguro, BA, Brasil. 
de Privação de Liberdade na FE-USP. Presidiu o referido curso, onde agregou pesquisadores e profissionais da educação básica e superior.

O título do livro, por si, levanta questões que se relacionam a inquietações decorrentes da prática docente e da pesquisa na área, sobretudo a partir da publicação, em 2010, das Diretrizes Nacionais para a oferta de educação para jovens e adultos em situação de privação de liberdade pelo Conselho Nacional de Educação. Apesar do avanço normativo e da pretensa indução de políticas públicas, há limitantes estruturais e operacionais nesses espaços que incidem na prática educativa, razão pela qual há um desafio permanente que paira sobre o trabalho educacional. Diante disso, a obra aponta caminhos possíveis, com metodologias que incluem formas de se organizar e articular os componentes curriculares nas áreas do conhecimento, considerando-se as experiências prévias dos estudantes, bem como as peculiaridades do contexto.

O livro tem três partes. A primeira contextualiza a proposta pedagógica para docência em regimes de privação de liberdade, o perfil de escolaridade de jovens e adultos em privação de liberdade, além da fundamentação legal sobre o tema. A segunda parte reflete os marcos teóricos e metodológicos da proposta, pautados no universo, na natureza e no ser humano como matrizes de aprendizagem. A partir disso, são elaborados esquemas de análise e interpretação do ser humano e de mapas conceituais por área, em que os componentes teóricos e didáticos são refletidos, culminando nos processos de avaliação de competências e habilidades. Por fim, a terceira parte descreve o processo de criação coletiva, que em uma polifonia de vozes se encerra em relatos de experiências dos profissionais da educação participantes do curso e da elaboração da proposta.

Os fundamentos da proposta pedagógica remontam as categorias ontológicas e biológicas da aprendizagem humana, cuja “didática no cárcerè é pensada em torno da natureza. Referencia-se nos marcos da Pedagogia Social, cuja compreensão do processo educacional, da construção do conhecimento e da educação ao longo da vida é mais relevante que dominar códigos ou técnicas.

Considerando o contexto da privação de liberdade e o perfil das pessoas encarceradas - majoritariamente jovem, negro e com escolaridade básica incompleta — argumenta-se que é possível contribuir para o desenvolvimento das habilidades e competências sociais e socioemocionais, a partir da associação da dinâmica da vida natural e humana. Opta-se por uma abordagem que se traduza em múltiplas alfabetizações e que possibilite ao sujeito compreender a dinâmica da vida em suas variadas manifestações, isto é, exploram-se as leis naturais, as formas de organização e complexificação das plantas, animais e da sociedade. Entende-se que, assim, o sujeito poderá compreender o sentido e a singularidade da vida humana no contexto do mundo em que vive.

Portanto, a proposta parte da própria origem da vida, em que o humano se insere e decorre, para construir as bases matriciais de aprendizagem e fundamentar as competências e habilidades que comporão escolhas metodológicas suficientemente flexíveis, transversais e contextualizadas, dadas as peculiaridades da educação no espaço prisional - por exemplo, a rotatividade de alunos e as restrições de uso de alguns materiais. 
A construção das matrizes de aprendizagem, por área do conhecimento, tem início em pressupostos do processo de compreensão do mundo natural. Por exemplo: a ideia de reinos na natureza e do átomo como partícula básica para a organização das moléculas, das quais originam todos os seres e suas diferenciações. São utilizadas palavras-chave das ciências da natureza, das quais decorrem conceitos e estruturas, para delinear as matrizes e se chegar às ciências humanas e sociais, matemática, linguagens e suas tecnologias. Isso explicaria o subtítulo da obra, "entender a natureza para entender o ser humano e seu mundo".

Ao discutir possibilidades epistemológicas, a obra sinaliza que é possível inferir formas de pensar e agir e apresenta um quadro elucidativo dos esquemas de análise e interpretação do ser humano, composto por forma de pensar (exemplo: marxista), categorias de análise (explorador/explorado), gradiente de comportamentos e atitudes (contestação) e formas de solução (revolução).

Ainda, discutem-se componentes avaliativos que valorizam habilidades e competências sociais, com destaque para os saberes construídos no mundo do trabalho e da vida. Busca-se exaltar as trajetórias singulares de vida e seus percursos (biológicos, cognitivos e sociais), em estreita consonância com a perspectiva da educação ao longo da vida, que implica uma visão ampliada de aprendizagens nos diversos espaços e tempos - escolares e não escolares.

Quanto às contribuições do livro para a área, é preciso considerar que, após a garantia do direito à educação das pessoas em privação de liberdade no Brasil, novas questões emergiram, com ênfase em práticas e pesquisas direcionadas à implementação de políticas pelo Estado e à prática docente. Verifica-se que a maior parte das publicações relaciona-se ao campo das políticas públicas, dos estudos de caso, das experiências das redes de ensino e do estudo de representações de estudantes, docentes e gestores ${ }^{2}$. Apenas mais recentemente, fundamentos epistemológicos e metodológicos têm se apresentado, representando ainda um campo fronteiriço e em crescente discussão na educação ${ }^{3}$. Assim, na ausência de materiais didáticos e de pesquisas sobre metodologias de ensino voltadas aos contextos de privação de liberdade, a prática docente segue, em geral, caminhos entre a adaptação de materiais disponíveis e o planejamento individual.

2 Publicações na área da Educação, após vigência das Diretrizes Nacionais, focam nos desafios e nas perspectivas para a política de educação em prisões. Nesse sentido, os dossiês temáticos publicados pela Revista Em Aberto, do INEP “Educação em Prisões”, em 2012 (disponível em: http://portal.inep.gov.br/documents/186968/485895/Educa\%C3\%A7\% C3\%A3o+em+pris\%C3\%B5es/8b4d6cb0-12db-4ad8-87fc-47e7c52a6153?version=1.3, acesso em: 12 mar. 2020), pela revista Educação e Realidade, da UFRGS, em 2013 (disponível em: https://seer.ufrgs.br/educacaoerealidade/issue/view/2030, acesso em: 20 mar. 2020) e pela revista Cadernos Cedes da UNICAMP "Educação, Escolarização e Trabalho em prisões" em 2016 (disponível em: https://www.scielo.br/scielo.php?script=sci_artt ext\&pid=S0101-32622016000100001, acesso em: 02 abr. 2019).

3 Nesse sentido, o artigo "Fundamentos epistemológicos para uma EJA prisional no Brasil”, de Roberto da Silva, na Revista Brasileira de Execução Penal, v. 1, n. 1, 2020. Disponível em: https://rbepdepen.mj.gov.br/index.php/RBEP/article/view/49. Acesso em: 30 abr. 2020. 
Demonstra-se, na obra, um esforço em produzir um material que reúna um conhecimento relevante do ponto de vista teórico-metodológico - enfaticamente para e por docentes. Fica evidente o engajamento em agregar diferentes atores ligados à área, com destaque para a construção da obra no âmbito de um curso que indica a salutar complementaridade entre educação básica e superior e a imprescindível polifonia de vozes na educação.

Destarte, sua relevância assenta-se não apenas na apresentação de uma proposta pedagógica específica, mas no processo de elaboração coletiva de metodologias e abordagens avaliativas que levem em conta os sujeitos e o contexto do ensino. Em particular, vale destacar que os esquemas apresentados no livro para a construção de mapas conceituais das áreas do conhecimento, com indicação gráfica de temas e questões pedagógicas de cada área, representam um contributo valoroso à comunicação, à síntese e à reflexão conceitual no âmbito da organização didática.

\section{REFERÊNCIAS}

SILVA, R. (org.). Didática no cárcere: entender a natureza para entender o ser humano e o seu mundo. São Paulo: Giostri, 2017.

SILVA, R. (org.). Didática no cárcere II: entender a natureza para entender o ser humano e o seu mundo. São Paulo: Giostri, 2018.

\section{SOBRE A AUTORA}

Carolina Bessa Ferreira de Oliveira é doutora em educação pela Universidade de São Paulo (USP). Professora da Universidade Federal do Sul da Bahia (UFSB).

E-mail: cbessafo@gmail.com

Recebido em 20 de junbo de 2020

Aprovado em 17 de setembro de 2020 